\title{
Design of CPW-Fed Slot Antenna with Rhombus Patch for loT Applications
}

\author{
Yuh-Yih Lu*, Yu-Ching Lin \\ Email address: \\ yylu@must.edu.tw (Yuh-Yih Lu) \\ ${ }^{*}$ Corresponding author
}

Department of Electrical Engineering, Minghsin University of Science and Technology, Hsinchu, Taiwan

\section{To cite this article:}

Yuh-Yih Lu, Yu-Ching Lin. Design of CPW-Fed Slot Antenna with Rhombus Patch for IoT Applications. International Journal of Wireless Communications and Mobile Computing. Vol. 5, No. 2, 2017, pp. 6-14. doi: 10.11648/j.wcmc.20170502.11

Received: May 26, 2017; Accepted: July 3, 2017; Published: July 19, 2017

\begin{abstract}
A CPW-fed slot antenna with rhombus patch radiator is proposed for 1.2276/1.5754/1.8/2.4/2.45/5.0/5.2/5.8 GHz wireless communication applications. The pentagon and rectangular slots are etched on the metallic layer of a single sided printed circuit board and rhombus patch radiator with a tuning stub in the feeding structure is embedded to form the proposed slot antenna. The dimensions of pentagon slot and tuning stub are changed to design and fabricate the antenna which can be operated at 1.2276/1.5754/1.8/2.4/2.45/5.0/5.2/5.8 GHz successfully. IE3D software is used to design this CPW-fed slot antenna and choose the better parameters to manufacture the proposed antenna. The influences of slot and stub dimension parameters of the proposed antenna on resonant frequency, input reflection coefficient expressed in decibel and impedance bandwidth are described. The proposed antenna with the volume of $100 \mathrm{~mm} \times 80 \mathrm{~mm} \times 0.6 \mathrm{~mm}$ has been fabricated. The measured result shows that the proposed antenna can be successfully operated at 1.2-2.8 GHz and 3.35-7.56 GHz bands. These bands are suitable for IoT-based applications.
\end{abstract}

Keywords: CPW, Rhombus Patch, Pentagon Slot, IoT

\section{Introduction}

In recent years, internet of things (IoT) is becoming part of every aspect of our lives. The application areas for the IoT are enormous including smart home, smart city, wireless sensor network, remote diagnostic, wireless surveillance, industrial automation, and so on. In IoT infrastructure, wireless connectivity combined with advanced sensor networks provide opportunities available for business in a smarter manner. Antenna is the key element for wireless communication. Compact size, lower cost and easy fabrication play an important role to design antenna that can be used in wireless commercial products. Coplanar antennas possess these attractive features. Hence, many articles about planar antennas had been studied and widely used in Global positioning System (GPS), Radio Frequency Identification (RFID), and Wireless Local Area Network (WLAN) systems [1-7]. Wireless communication devices relating to the field of IoT are developed rapidly. These information devices should be capable of large bandwidth and can be operated at multiple frequencies. Bandwidth enhancement in antenna design can meet the need for increasing the data transfer. This requirement can be achieved using the slot antenna techniques [8-9]. Many researches have also been reported for multi-band and ultra-wideband planar antenna [10-14] which can provide various operating frequencies.

In this study, a simple coplanar waveguide (CPW) feed slot antenna with rhombus patch radiator is proposed. The operating frequency band and impedance bandwidth are obtained from IE3D simulations. The structure parameters of the pentagon slot and tuning stub control the operating frequency band of the CPW-fed slot antenna. The proposed antenna excites the resonant frequency that can be used for GPS (1227.6/1575.4MHz), TD-SCDMA (2.01-2.025GHz), WLAN (2.4-2.484GHz), RFID (2.45/5.8GHz), public safety application $(4.94-4.99 \mathrm{GHz})$, and $802.11 \mathrm{a}$ standard $(5.15-5.35$ $\mathrm{GHz}$ ). The suitable geometric parameters of the pentagon slot and tuning stub are chosen to fabricate the proposed antenna. Therefore, a simple CPW-fed slot antenna with the size of $100 \mathrm{~mm} \times 80 \mathrm{~mm} \times 0.6 \mathrm{~mm}$ is presented in this paper. The configuration of the proposed $\mathrm{CPW}$-fed slot antenna is presented in section 2 while the simulation and experimental 
results including discussion are described in section 3 and 4.

\section{Antenna Design}

The proposed CPW-fed slot antenna with rhombus patch radiator structure is printed on a single metallic layer of FR4 dielectric substrate which has permittivity of 4.4 and thickness of $0.6 \mathrm{~mm}$. The configuration of this proposed antenna is shown in Figure 1.
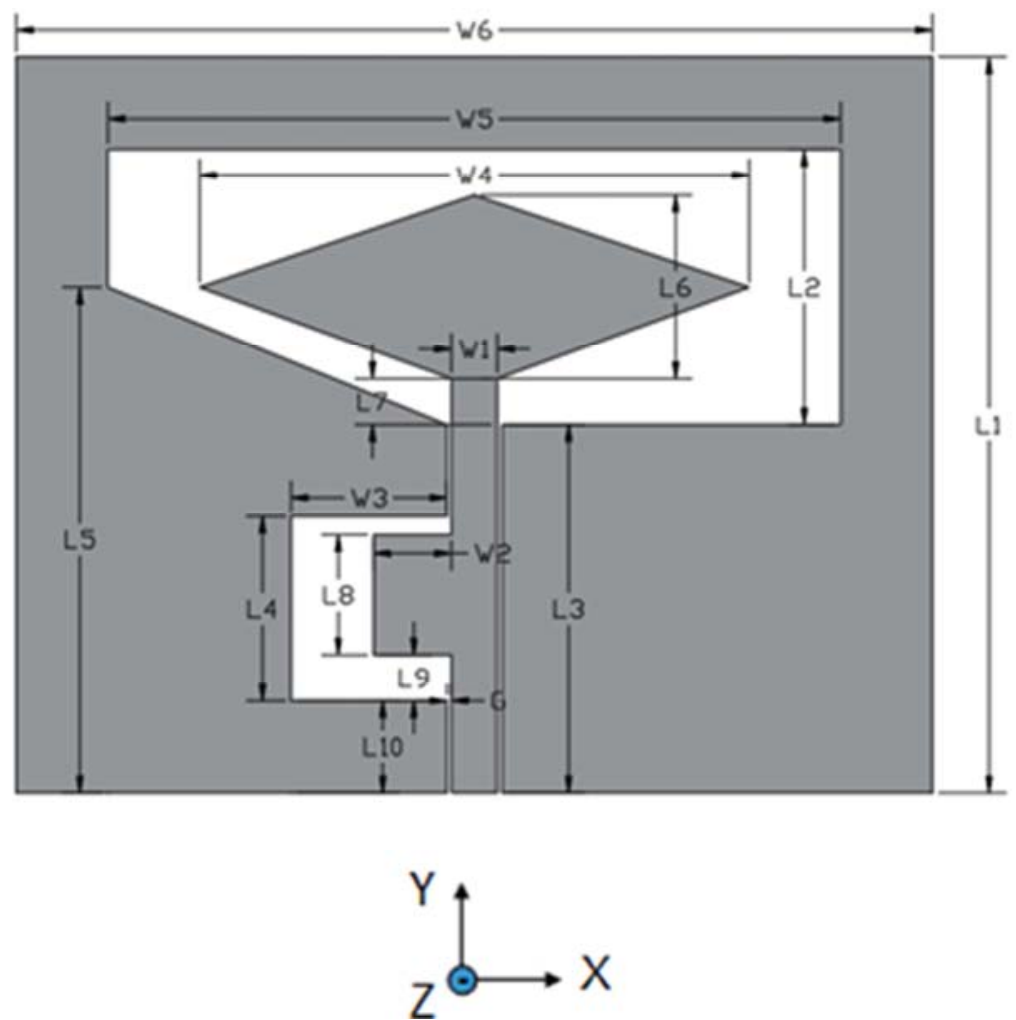

Figure 1. Geometry of the proposed slot antenna.

In this figure, the pentagon and rectangular slots are etched on the metallic layer and rhombus patch radiator with a tuning stub in the feeding structure is embedded to create the operating frequency bands. The pentagon slot structure parameter L5 and tuning stub size parameter W2 are adjusted to observe the variations with respect to resonant frequency $\left(\mathrm{f}_{0}\right)$, input reflection coefficient expressed in decibel $\left(\mathrm{S}_{11}\right)$, lower frequency band limit $\left(\mathrm{f}_{1}\right)$, upper frequency band limit $\left(\mathrm{f}_{2}\right)$, and impedance bandwidth (BW) of the proposed antennas. The dimension parameters of the proposed CPW-fed slot antenna shown in Figure 1 are listed below: $\mathrm{W} 1=5 \mathrm{~mm}, \quad \mathrm{~W} 3=17 \mathrm{~mm}, \quad \mathrm{~W} 4=60 \mathrm{~mm}, \quad \mathrm{~W} 5=80 \mathrm{~mm}$, $\mathrm{W} 6=100 \mathrm{~mm}, \mathrm{G}=0.5 \mathrm{~mm}, \mathrm{~L} 1=80 \mathrm{~mm}, \mathrm{~L} 2=30 \mathrm{~mm}, \mathrm{~L} 3=40 \mathrm{~mm}$, $\mathrm{L} 4=20 \mathrm{~mm}, \mathrm{~L} 6=20 \mathrm{~mm}, \mathrm{~L} 7=5 \mathrm{~mm}, \mathrm{~L} 8=13 \mathrm{~mm}, \mathrm{~L} 9=5 \mathrm{~mm}$, and $\mathrm{L} 10=10 \mathrm{~mm}$. The $50 \mathrm{ohm}$ coaxial connector was adopted for testing.

\section{The Simulations}

Various dimension parameters L5 and W2 shown in Figure 1 of the CPW-fed slot antenna are adopted to observe the characteristics of the proposed antenna. The numerical simulation and analysis for the proposed antennas are performed using IE3D simulation software. The simulated curves of $S_{11}$ against frequency for varying the pentagon slot parameter L5 of the proposed antenna with $\mathrm{W} 2=8.5 \mathrm{~mm}$ are depicted in Figure 2. The simulated results including resonant frequency $\left(\mathrm{f}_{0}\right)$, input reflection coefficient expressed in decibel $\left(\mathrm{S}_{11}\right)$, lower frequency band limit $\left(\mathrm{f}_{1}\right)$, upper frequency band limit $\left(\mathrm{f}_{2}\right)$, and impedance bandwidth $(\mathrm{BW})$ are listed in Table1.

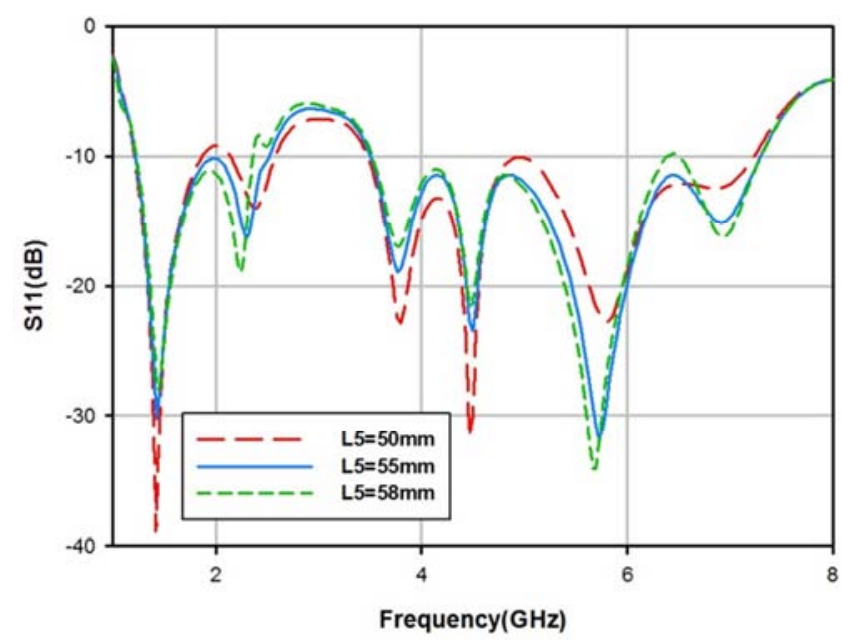

Figure 2. Simulated curves of $S_{11}$ against frequency for varying $L 5$ of the proposed slot antenna with $W 2=8.5 \mathrm{~mm}$.

From Figure 2 and Table 1, three or two operating 
frequency bands are observed with changing pentagon slot parameter L5. The lowest resonant frequency is nearly unchanged but the higher resonant frequency is shifted to higher frequency with increasing the value of L5. At the lower frequency band (1.21-2.58GHz), two operating bands merge into one band with increasing L5. At the higher frequency band $(3.47-7.29 \mathrm{GHz})$, the operating frequency band splits into two bands when L5 $=58 \mathrm{~mm}$. Therefore, suitable pentagon slot parameter L $5=55 \mathrm{~mm}$ will excite two valuable frequency bands and exhibit larger bandwidth of the proposed antenna. The simulated curves of $S_{11}$ against frequency for varying tuning stub parameter $\mathrm{W} 2$ of the proposed antenna with L5 $=55 \mathrm{~mm}$ is shown in Figure 3. The simulated results from Figure 3 are also listed in Table 2.

From Figure 3 and Table 2, three or two operating frequency bands are also observed with changing tuning stub parameter W2. Tuning stub added in the feeding structure can enhance the impedance bandwidth. Therefore, dual band merges into single band at the lower frequency band (1.21 $-2.56 \mathrm{GHz})$. At higher frequency band (3.99 -7.29GHz), BW increases first and then decreases with increasing the value of W2. In the rectangular slot ground plane, the tuning stub can not only enhance the coupling effect but also perturb the current distribution.

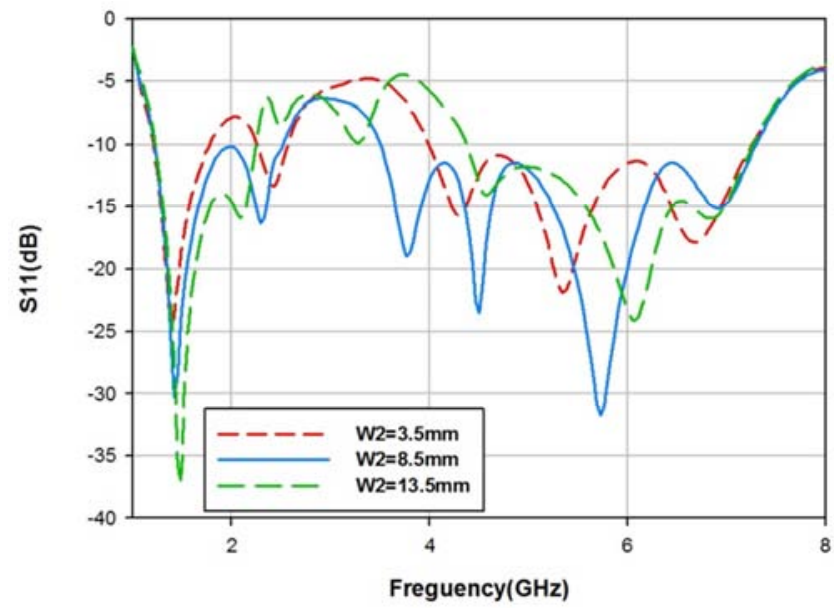

Figure 3. Simulated curves of $S_{11}$ against frequency for varying $W 2$ of the proposed slot antenna with $\mathrm{L} 5=55 \mathrm{~mm}$.

Table 1. Simulated results of the proposed slot antenna with $\mathrm{W} 2=8.5 \mathrm{~mm}$.

\begin{tabular}{lllll}
\hline $\mathbf{L 5}$ & $\mathbf{f}_{\mathbf{0}}$ & $\mathbf{S}_{\mathbf{1 1}}$ & $\mathbf{f}_{\mathbf{1}}, \mathbf{f}_{\mathbf{2}}$ & $\mathbf{B W}$ \\
\hline $\mathbf{( m m )}$ & $\mathbf{( G H z )}$ & $\mathbf{( d B )}$ & $\mathbf{( G H z )}$ & $\mathbf{( G H z )}$ \\
\hline 50 & 1.42 & -37.25 & $1.21,1.87$ & 0.66 \\
& 2.38 & -14.02 & $2.14,2.58$ & 0.44 \\
& 4.47 & -31.44 & $3.47,7.23$ & 3.76 \\
55 & 1.42 & -30.10 & $1.22,2.51$ & 1.29 \\
& 5.73 & -31.57 & $3.50,7.29$ & 3.79 \\
58 & 1.43 & -27.77 & $1.22,2.36$ & 1.14 \\
& 5.67 & -34.11 & $3.52,6.39$ & 2.87 \\
& 6.92 & -16.22 & $6.49,7.29$ & 0.80 \\
\hline
\end{tabular}

The tuning stub with W2 equals to $3.5 \mathrm{~mm}$ exhibit more operating band characteristics of the proposed antenna. In other word, the smaller size of tuning stub results in impedance mismatch at the lower frequency band
(1.21-2.56GHz). The upper frequency band limit $\left(\mathrm{f}_{2}\right)$ of the proposed slot antenna is nearly unchanged but the lower frequency band limit $\left(f_{1}\right)$ decreases first and then increases with increasing the value of W2 at the higher frequency band (3.50-7.29GHz). Therefore, the tuning stub with W2 equals to $8.5 \mathrm{~mm}$ exhibits better bandwidth of the proposed antenna. Carefully adjusting the pentagon slot parameter L5 and tuning stub size parameter W2 of the proposed antenna is very important to design the CPW-fed slot antenna that can be used at 1.2-2.8 GHz and 3.35-7.56 GHz bands.

Table 2. Simulated results of the proposed slot antenna with $\mathrm{L} 5=55 \mathrm{~mm}$.

\begin{tabular}{lllll}
\hline $\mathbf{W} 2$ & $\mathbf{f}_{\mathbf{0}}$ & $\mathbf{S}_{\mathbf{1 1}}$ & $\mathbf{f}_{\mathbf{1}}, \mathbf{f}_{\mathbf{2}}$ & $\mathbf{B W}$ \\
\hline $\mathbf{( m m})$ & $\mathbf{( G H z )}$ & $\mathbf{( d B )}$ & $\mathbf{( G H z )}$ & $\mathbf{( G H z )}$ \\
\hline 3.5 & 1.39 & -24.42 & $1.21,1.77$ & 0.56 \\
& 2.42 & -13.29 & $2.26,2.56$ & 0.30 \\
& 5.35 & -21.85 & $3.99,7.25$ & 3.26 \\
8.5 & 1.42 & -30.10 & $1.22,2.51$ & 1.29 \\
& 5.73 & -31.57 & $3.50,7.29$ & 3.79 \\
13.5 & 1.48 & -37.24 & $1.23,2.24$ & 1.01 \\
& 6.05 & -24.02 & $4.37,7.26$ & 2.89 \\
\hline
\end{tabular}

\section{Experimental Results and Discussion}

Figure 4 shows the photography of traditional CPW-fed rectangular slot antenna with rhombus patch radiator. The simulation and measurement results of this antenna are depicted in Figure 5 and listed in Table 3 including $\mathrm{f}_{0}, \mathrm{~S}_{11}, \mathrm{f}_{1}$, $\mathrm{f}_{2}$, and $\mathrm{BW}$.

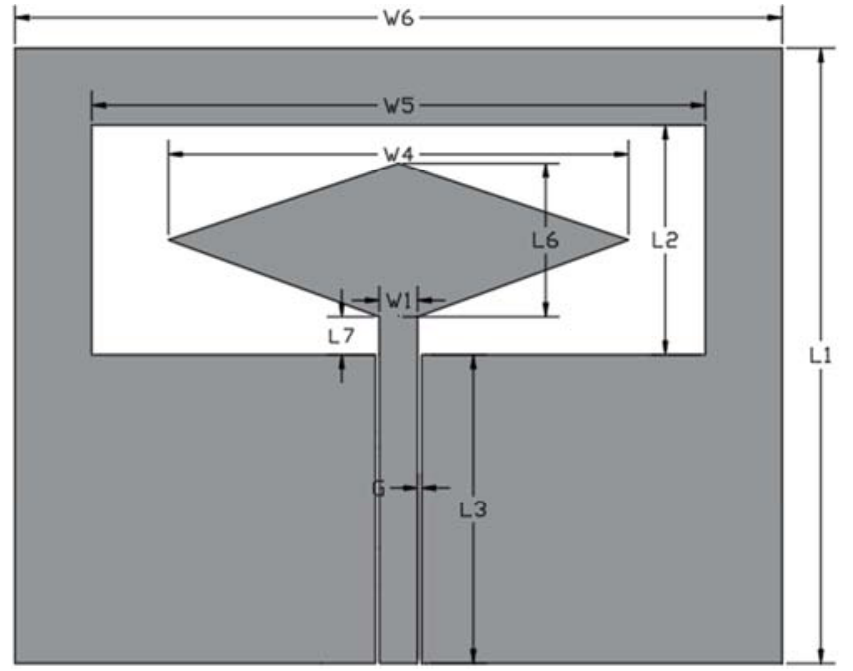

Figure 4. Geometry of the traditional $C P W$-fed slot antenna with rhombus patch.

Table 3. Simulated and measured results of traditional CPW-fed slot antenna with rhombus patch.

\begin{tabular}{lllll}
\hline & $\mathbf{f}_{\mathbf{0}}$ & $\mathbf{S}_{\mathbf{1 1}}$ & $\mathbf{f}_{\mathbf{1}}, \mathbf{f}_{\mathbf{2}}$ & $\mathbf{B W}$ \\
\hline & $\mathbf{( G H z})$ & $\mathbf{( d B})$ & $\mathbf{( G H z )}$ & $\mathbf{( G H z )}$ \\
\hline Simulation & 1.35 & -23.75 & $1.11,2.79$ & 1.68 \\
& 4.14 & -11.62 & $4.02,4.30$ & 0.28 \\
& 6.39 & -11.18 & $6.25,7.05$ & 0.80 \\
Measurement & 1.30 & -17.72 & $1.10,1.73$ & 0.63 \\
\hline
\end{tabular}




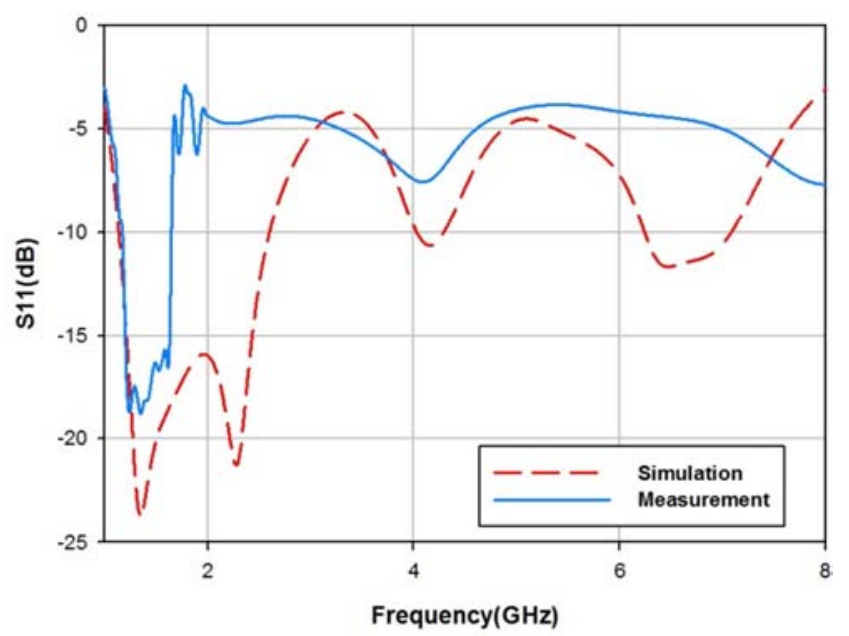

Figure 5. Simulated and measured $S_{11}$ against frequency for traditional $C P W$-fed slot antenna with rhombus patch.

From Figure 5 and Table 3, the simulation results show that three operating frequency bands can be achieved. However, only single operating frequency band can be excited for the traditional $\mathrm{CPW}$-fed rectangular slot antenna with rhombus patch radiator from the measured results because of the effect of the coaxial connector soldering process and fabrication tolerance. From the simulation results described in section 3 , it is easily observed that the CPW-fed slot antenna with pentagon and rectangular slots, rhombus patch radiator, tuning stub in the feeding structure exhibits dual operating frequency bands. The proposed antenna exhibits more operating frequencies than the traditional CPW-fed rectangular slot antenna with rhombus patch radiator. The same geometric parameters as described in section 3 are used to fabricate the proposed $\mathrm{CPW}$-fed slot antenna. Photographs of fabricated CPW-fed slot antennas with changing L5 and fixing $\mathrm{W} 2=8.5 \mathrm{~mm}$ and with changing W2 and fixing L5 $=55 \mathrm{~mm}$ are shown in Figures 6 and 7 , respectively.

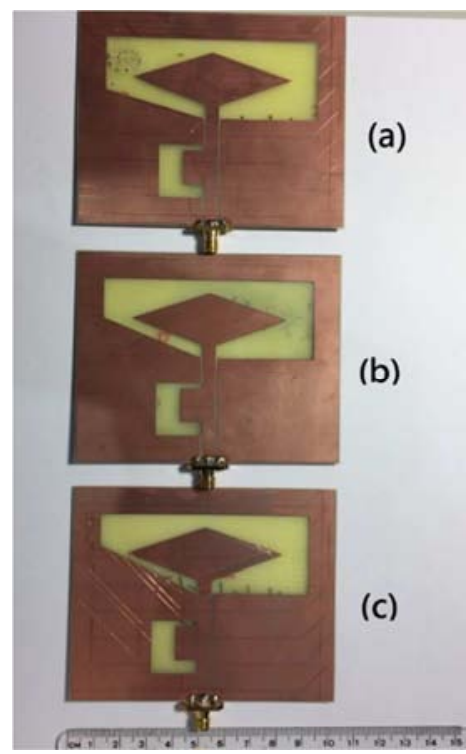

Figure 6. Photography of fabricated slot antenna with $W 2=8.5 \mathrm{~mm}$ and (a) $L 5=50 \mathrm{~mm}$ (b) $L 5=55 \mathrm{~mm}$ (c) $L 5=58 \mathrm{~mm}$.

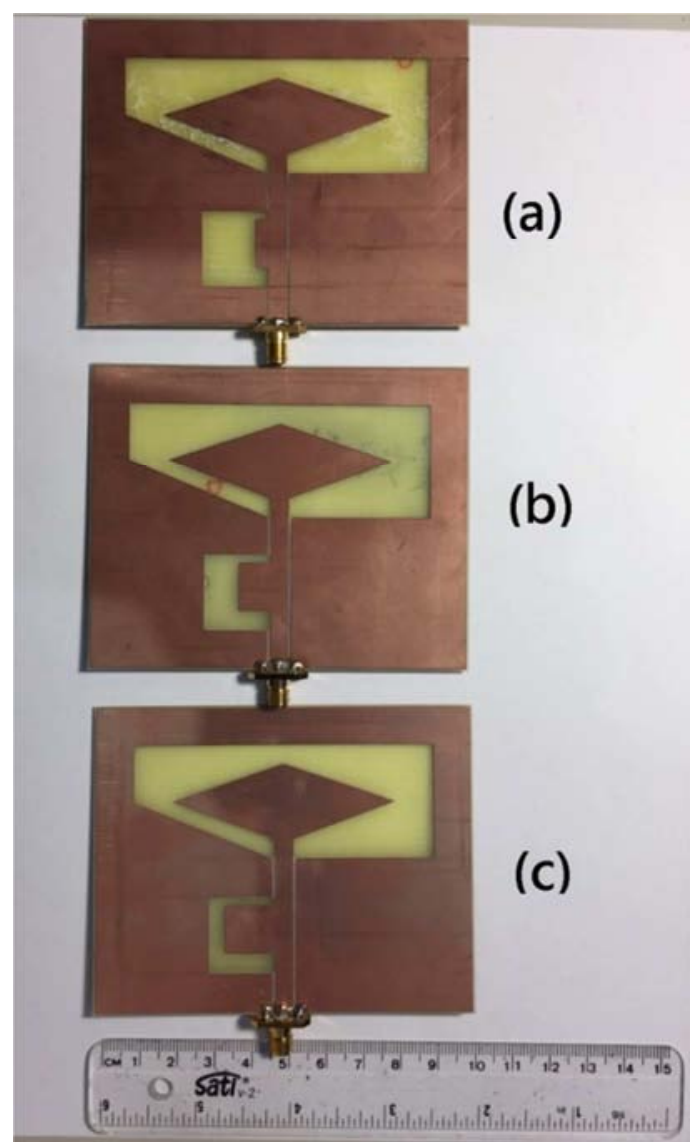

Figure 7. Photography of fabricated slot antenna with L5=55mm and (a) $W 2=3.5 \mathrm{~mm}$ (b) $W 2=8.5 \mathrm{~mm}$ (c) $W 2=13.5 \mathrm{~mm}$.

The measured curves of $S_{11}$ against frequency for varying the pentagon slot parameter L5 of the proposed antenna with $\mathrm{W} 2=8.5 \mathrm{~mm}$ are shown in Fig. 8 . The measured results including $\mathrm{f}_{0}, \mathrm{~S}_{11}, \mathrm{f}_{1}, \mathrm{f}_{2}$, and $\mathrm{BW}$ are listed in Table 4. From Figure 8 and Table 4, it can be seen that multiple operating frequency bands are also obtained at the lower frequency range $(1.20-3.19 \mathrm{GHz})$. The measured results show poor $\mathrm{S}_{11}$ performance than the simulated results which may come from impedance mismatching phenomenon because of the ground plane close to the rhombus patch radiator. Therefore, the measured results appear the additional operating band from $1.26 \mathrm{GHz}$ to $3.19 \mathrm{GHz}$ for the fabricated CPW-fed slot antenna with $\mathrm{L} 5=58 \mathrm{~mm}$. The multiple bands merges into single band at $1.20-3.19 \mathrm{GHz}$ for $\mathrm{L} 5=55 \mathrm{~mm}$.

Table 4. Measured results of the fabricated slot antenna with $W 2=8.5 \mathrm{~mm}$.

\begin{tabular}{lllll}
\hline $\mathbf{L 5}$ & $\mathbf{f}_{\mathbf{0}}$ & $\mathbf{S}_{\mathbf{1 1}}$ & $\mathbf{f}_{\mathbf{1}}, \mathbf{f}_{\mathbf{2}}$ & $\mathbf{B W}$ \\
\hline $\mathbf{( m m})$ & $\mathbf{( G H z )}$ & $\mathbf{( d B )}$ & $\mathbf{( G H z})$ & $\mathbf{( G H z )}$ \\
\hline 50 & 1.40 & -27.11 & $1.23,1.63$ & 0.40 \\
& 2.25 & -19.35 & $1.81,2.40$ & 0.59 \\
& 4.25 & -30.57 & $3.50,7.45$ & 3.95 \\
55 & 1.50 & -20.56 & $1.20,2.80$ & 1.60 \\
& 3.80 & -25.16 & $3.35,7.56$ & 4.21 \\
58 & 1.41 & -30.55 & $1.26,1.60$ & 0.34 \\
& 1.85 & -13.36 & $1.79,2.06$ & 0.27 \\
& 2.36 & -13.05 & $2.24,2.58$ & 0.34 \\
& 3.08 & -10.79 & $3.05,3.19$ & 0.14 \\
& 4.39 & -26.74 & $3.38,7.31$ & 3.93 \\
\hline
\end{tabular}




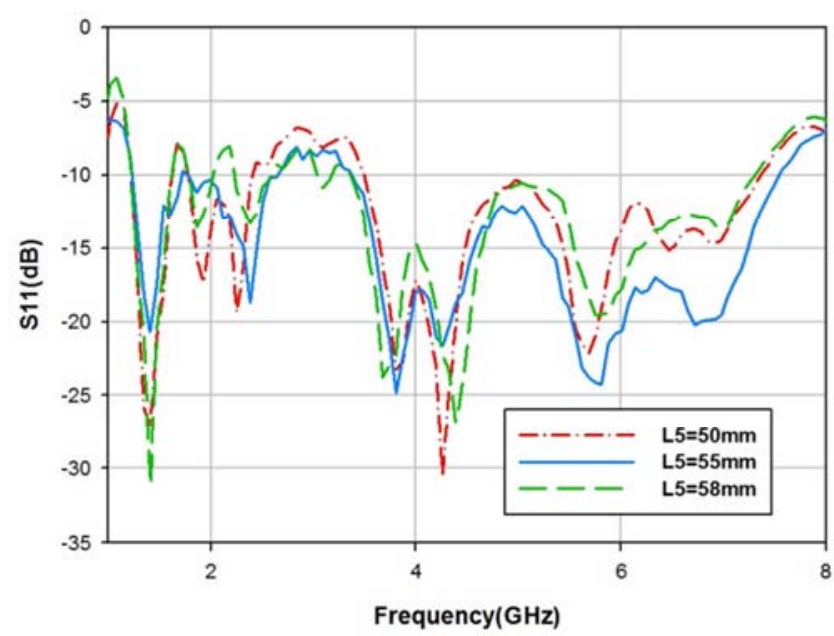

Figure 8. Measured $S_{11}$ against frequency of the fabricated slot antenna with $W 2=8.5 \mathrm{~mm}$.

The measured curves of $S_{11}$ against frequency for varying the tuning stub parameter W2 of the proposed antenna with L5 $=55 \mathrm{~mm}$ are shown in Fig.9. The measured results are also listed in Table 5. From Figure 9 and Table 5, the split band phenomenon has also been observed for $\mathrm{W} 2=3.5 \mathrm{~mm}$ which may come from poor impedance matching phenomenon. The measured $\mathrm{S}_{11}$ curves are slightly shifted to higher frequency compared with the simulated $\mathrm{S}_{11}$ curves. The trends of the measured results relate well with the simulated results.

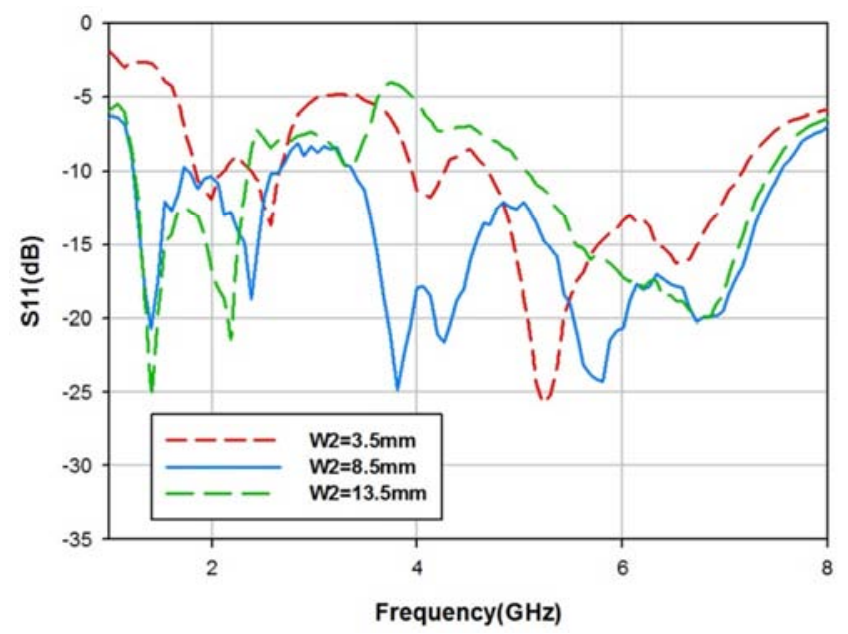

Figure 9. Measured $S_{11}$ against frequency of the fabricated slot antenna with L5 $=55 \mathrm{~mm}$.

Table 5. Measured results of the fabricated slot antenna with $L 5=55 \mathrm{~mm}$.

\begin{tabular}{lllll}
\hline $\mathbf{W} 2$ & $\mathbf{f}_{\mathbf{0}}$ & $\mathbf{S}_{\mathbf{1 1}}$ & $\mathbf{f}_{\mathbf{1}}, \mathbf{f}_{\mathbf{2}}$ & $\mathbf{B W}$ \\
\hline $\mathbf{( m m )}$ & $\mathbf{( G H z )}$ & $\mathbf{( d B )}$ & $\mathbf{( G H z )}$ & $\mathbf{( G H z )}$ \\
\hline 3.5 & 2.00 & -11.95 & $1.84,2.12$ & 0.28 \\
& 2.58 & -13.71 & $2.31,2.68$ & 0.37 \\
& 4.06 & -11.16 & $3.95,4.26$ & 0.31 \\
& 5.20 & -25.76 & $4.64,7.17$ & 2.53 \\
8.5 & 1.50 & -20.56 & $1.20,2.80$ & 1.60 \\
& 3.80 & -25.16 & $3.35,7.56$ & 4.21 \\
13.5 & 1.50 & -25.29 & $1.25,2.36$ & 1.11 \\
& 6.71 & -19.84 & $5.05,7.45$ & 2.40 \\
\hline
\end{tabular}

To reach the operating frequencies covering $1.2276 / 1.5754 / 1.8 / 2.4 / 2.45 / 5.0 / 5.2 / 5.8 \mathrm{GHz}$, the better performance antenna with $\mathrm{L} 5=55 \mathrm{~mm}$ and $\mathrm{W} 2=8.5 \mathrm{~mm}$ is used to study the characteristics of the proposed antenna. The curves of $\mathrm{S}_{11}$ against frequency of the simulated and fabricated antenna with $\mathrm{L} 5=55 \mathrm{~mm}$ and $\mathrm{W} 2=8.5 \mathrm{~mm}$ are illustrated in Figure 10. The simulated and measured results of this proposed antenna are listed in Table 6.

Table 6. Simulated and measured results of the fabricated slot antenna with $L 5=55 \mathrm{~mm}$ and $W 2=8.5 \mathrm{~mm}$.

\begin{tabular}{lllll}
\hline & $\mathbf{f}_{\mathbf{0}}$ & $\mathbf{S}_{\mathbf{1 1}}$ & $\mathbf{f}_{\mathbf{1}}, \mathbf{f}_{\mathbf{2}}$ & $\mathbf{B W}$ \\
\hline \multirow{2}{*}{ Simulation } & $\mathbf{( G H z )}$ & $\mathbf{( d B )}$ & $\mathbf{( G H z )}$ & $\mathbf{( G H z )}$ \\
& 1.42 & -30.10 & $1.22,2.51$ & 1.29 \\
\multirow{3}{*}{ Measurement } & 5.73 & -31.57 & $3.50,7.29$ & 3.79 \\
& 1.50 & -20.56 & $1.20,2.80$ & 1.60 \\
& 3.80 & -25.16 & $3.35,7.56$ & 4.21 \\
\hline
\end{tabular}

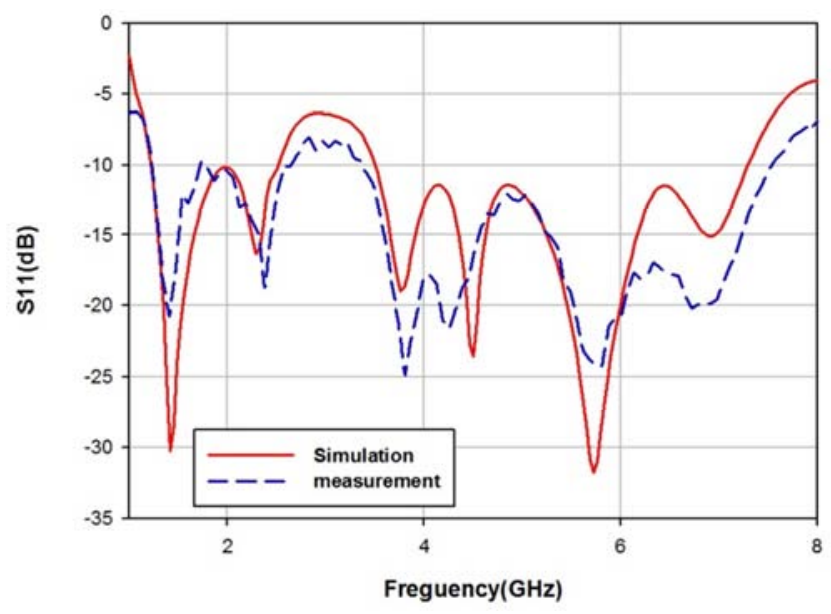

Figure 10. Simulated and measured $S_{11}$ against frequency of the proposed slot antenna with $\mathrm{L} 5=55 \mathrm{~mm}$ and $W 2=8.5 \mathrm{~mm}$.

From Figure 10 and Table 6, the dual-band phenomenon appears of the simulated and fabricated CPW-fed slot antenna with $\mathrm{L} 5=55 \mathrm{~mm}$ and $\mathrm{W} 2=8.5 \mathrm{~mm}$. The measured $\mathrm{S}_{11}$ curve of this fabricated antenna shifts to higher frequency compared with the simulated results. Hence, the measured impedance bandwidths of this fabricated antenna show better performance than that in simulation condition. There are discrepancies between the computed and measured results which may occur because of the effect of the coaxial connector soldering process and fabrication tolerance.

The measured radiation patterns of this fabricated antenna at 1.2276/1.5754/1.8/2.4/2.45/5.0/5.2/5.8 GHz are shown in Figure 11. The measured peak gains for testing frequencies at $x-z$ and $y-z$ plane of this fabricated antenna are listed in Table 7. From Figure 11, it can be observed that the radiation patterns are almost omnidirectional in the $y-z$ plane. The omnidirectional antenna radiation pattern indicates that the fabricated antenna is good for mobile devices. 

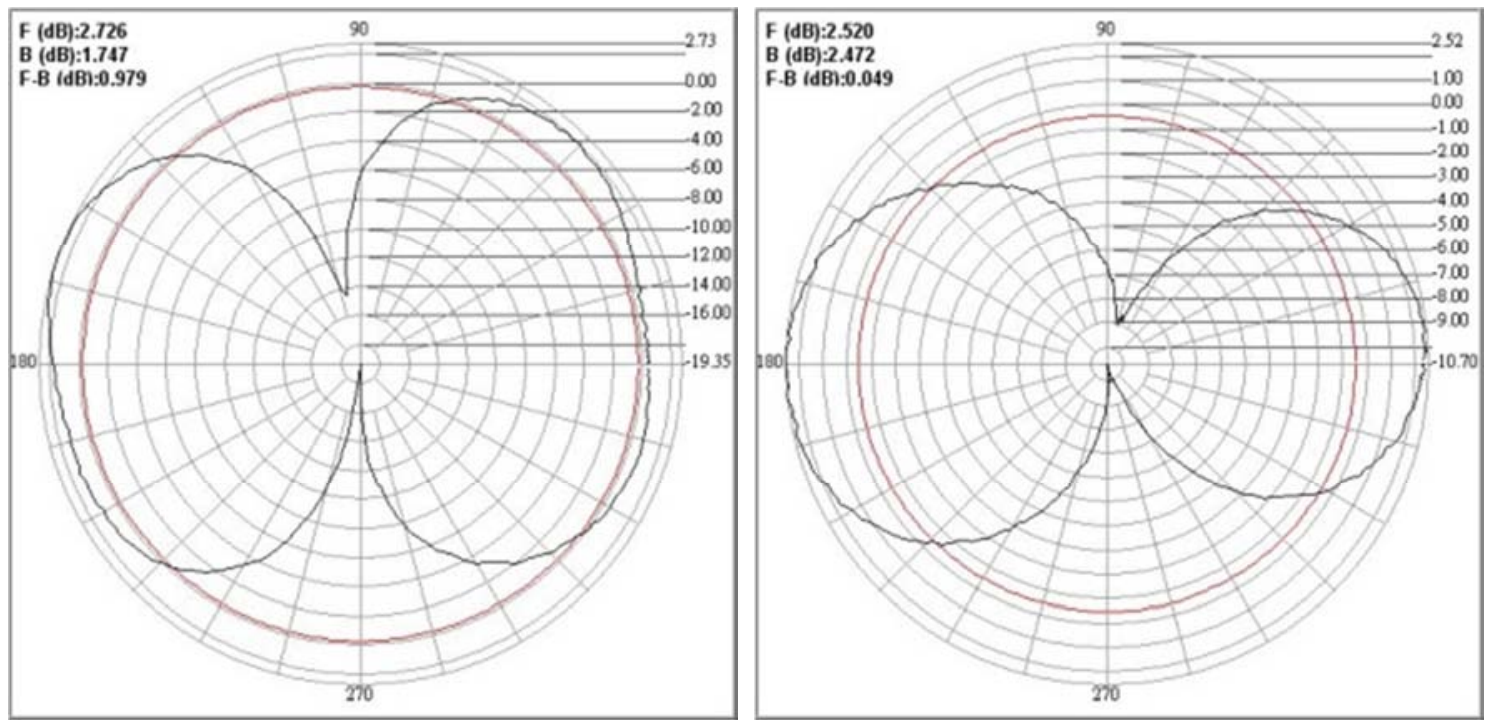

(a) $\mathrm{f}=1.2276 \mathrm{GHz} \mathrm{X}-\mathrm{Z}$ plane (b) $\mathrm{f}=1.2276 \mathrm{GHz} \mathrm{Y}-\mathrm{Z}$ plane
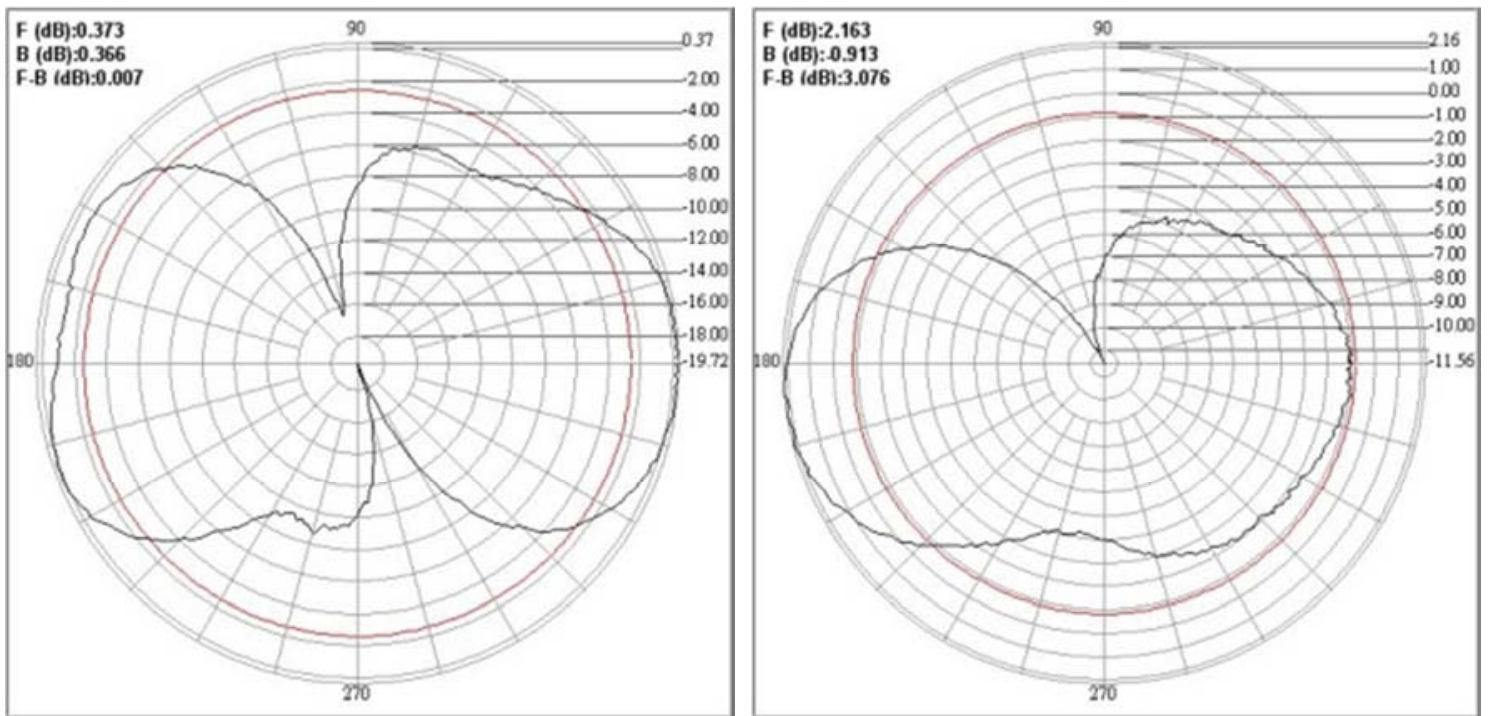

(c) $\mathrm{f}=1.5754 \mathrm{GHz} X-\mathrm{Z}$ plane (d) $\mathrm{f}=1.5754 \mathrm{GHz} \mathrm{Y}-\mathrm{Z}$ plane
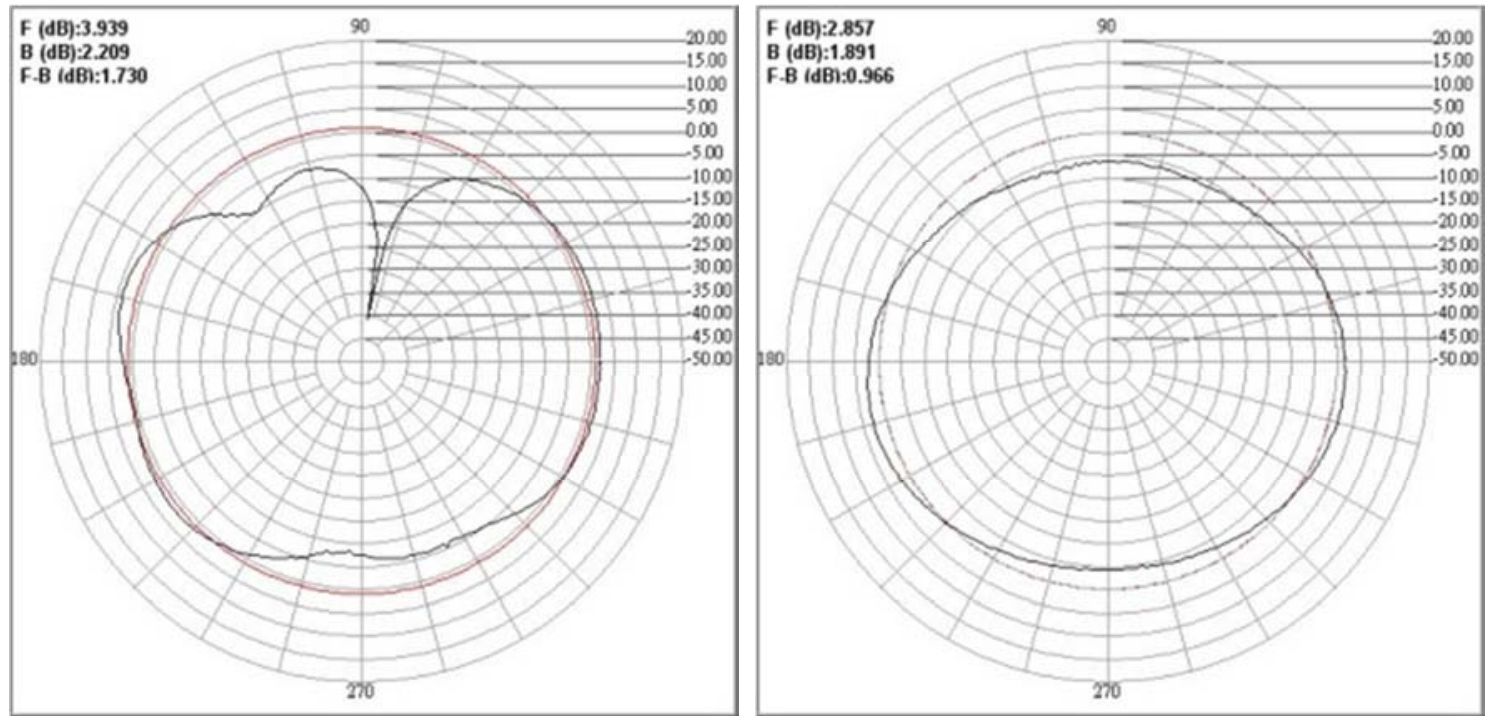

(e) $\mathrm{f}=1.8 \mathrm{GHz} \mathrm{X}-\mathrm{Z}$ plane (f) $\mathrm{f}=1.8 \mathrm{GHz} \mathrm{Y}-\mathrm{Z}$ plane 

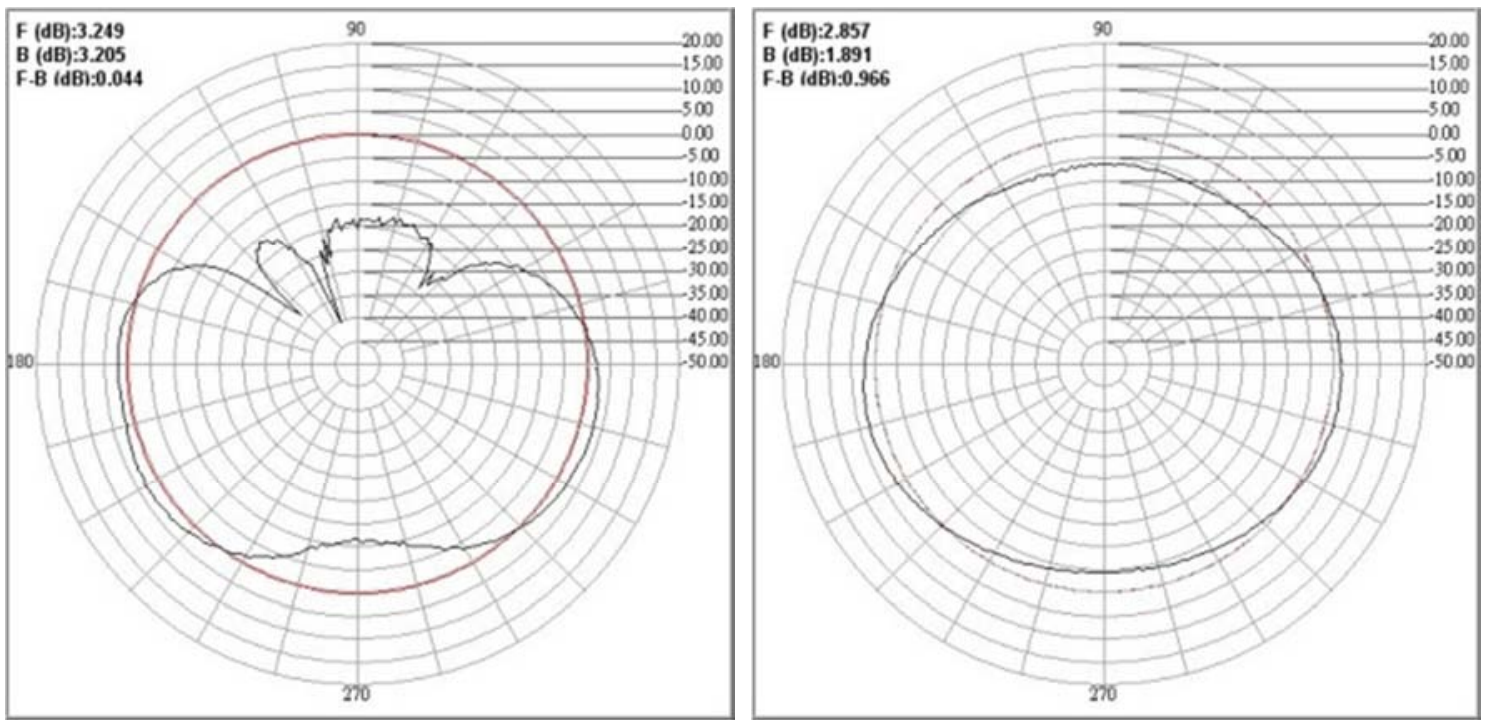

(g) f= 2.4 GHz X-Z plane (h) $\mathrm{f}=2.4 \mathrm{GHz}$ Y-Z plane
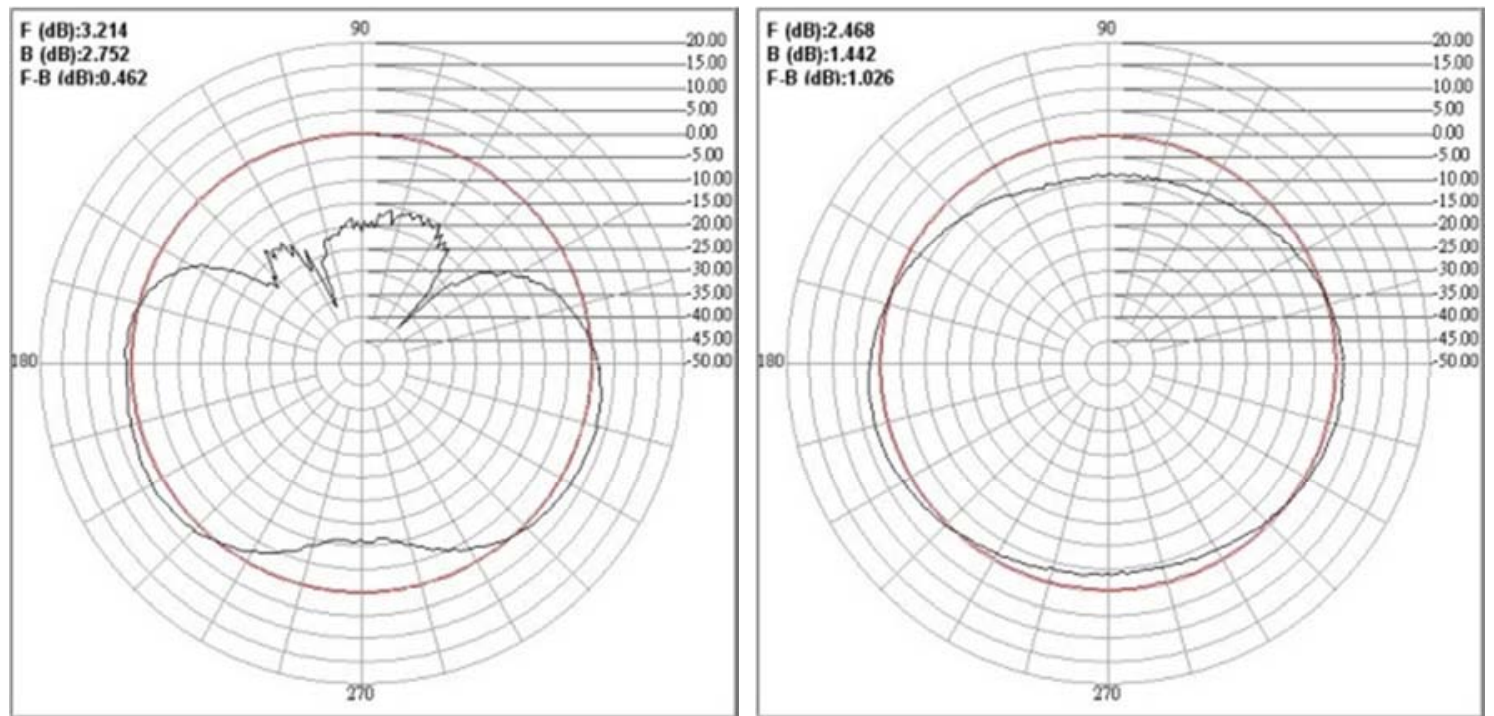

(i) $\mathrm{f}=2.45 \mathrm{GHz} \mathrm{X}-\mathrm{Z}$ plane (j) $\mathrm{f}=2.45 \mathrm{GHz} \mathrm{Y}-\mathrm{Z}$ plane
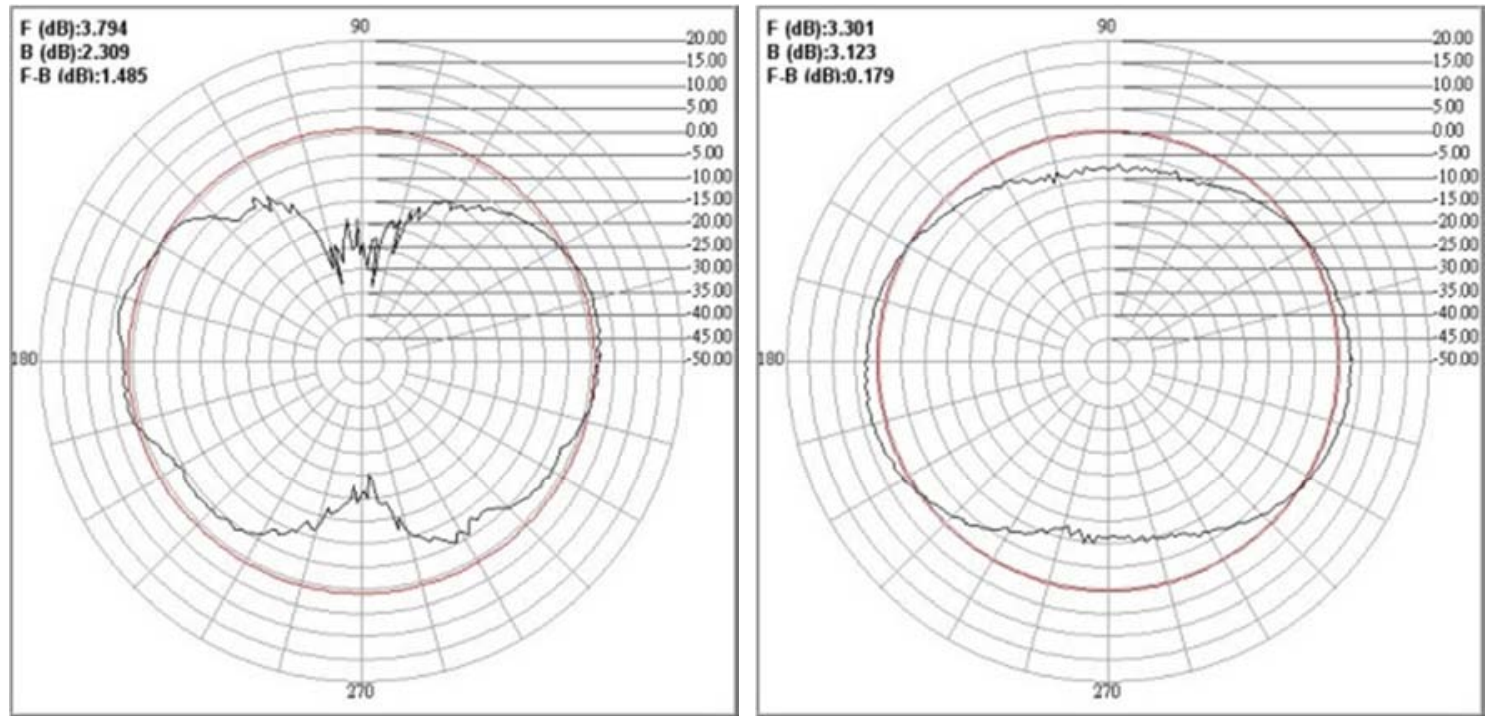

(k) f= 5.0 GHz X-Z plane (l) f= $=5.0 \mathrm{GHz} Y-Z$ plane 

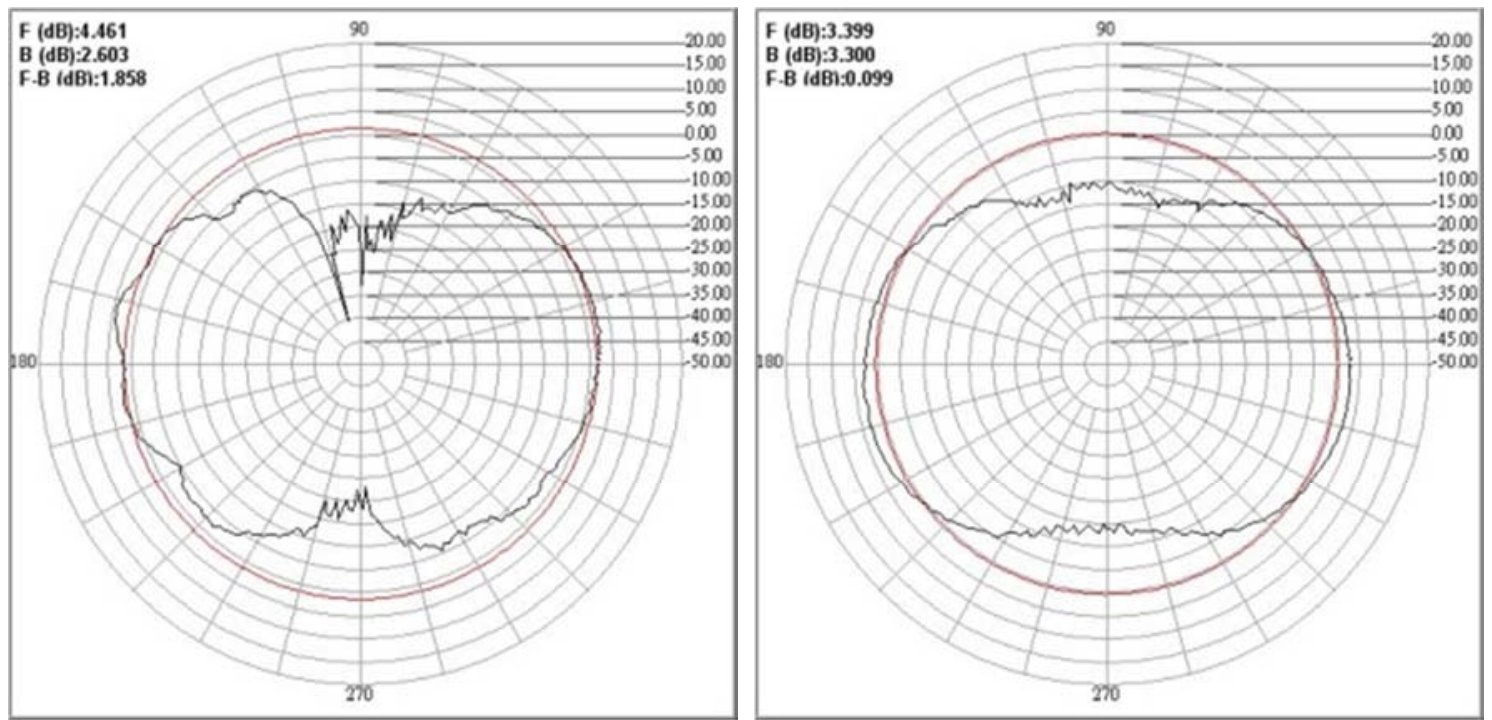

(m) $\mathrm{f}=5.2 \mathrm{GHz} X-\mathrm{Z}$ plane $(\mathrm{n}) \mathrm{f}=5.2 \mathrm{GHz} \mathrm{Y}-\mathrm{Z}$ plane
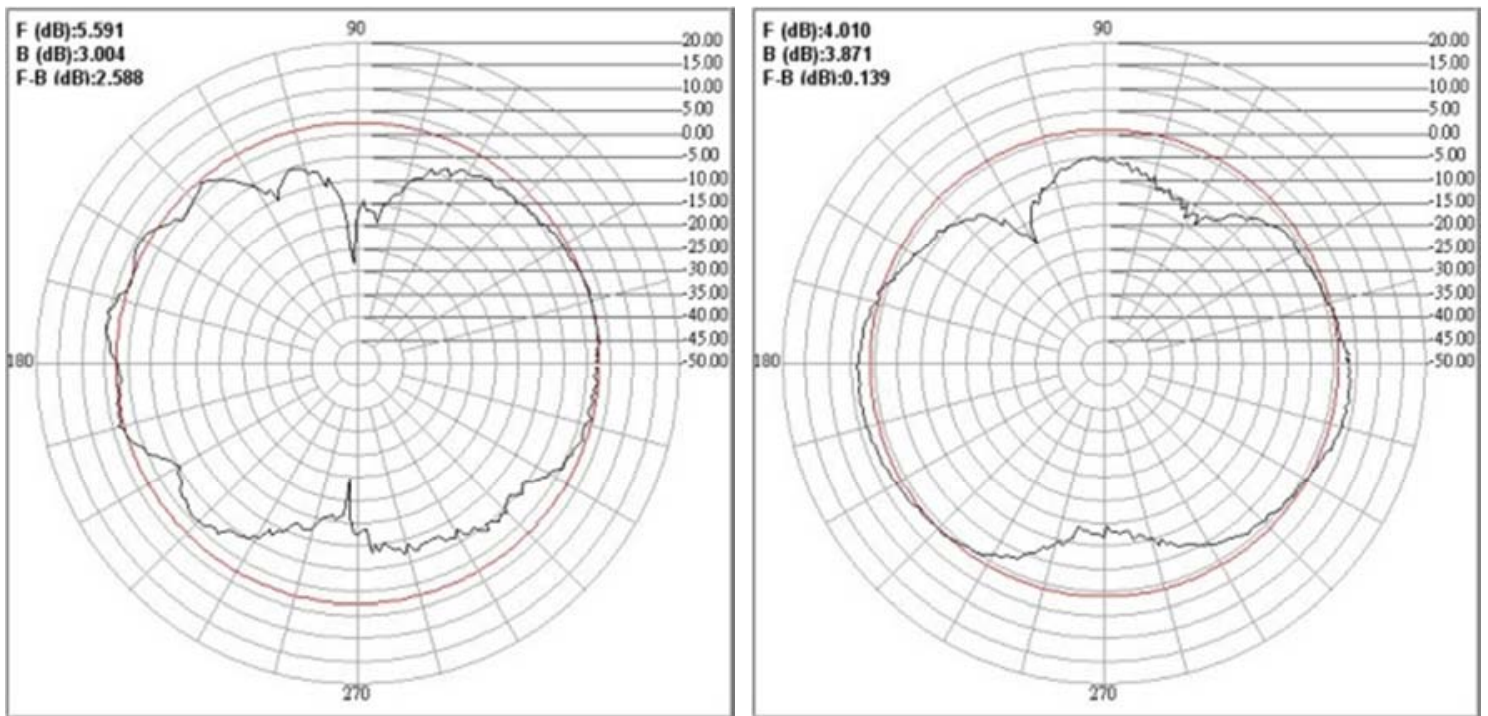

(o) $\mathrm{f}=5.8 \mathrm{GHz} X-\mathrm{Z}$ plane (p) $\mathrm{f}=5.8 \mathrm{GHz} \mathrm{Y}-\mathrm{Z}$ plane

Figure 11. Measured radiation patterns of the fabricated slot antenna with $L 5=55 \mathrm{~mm}$ and $W 2=8.5 \mathrm{~mm}$.

Table 7. Measured peak gains of the fabricated slot antenna with L5=55mm and $W 2=8.5 \mathrm{~mm}$ at operating frequency.

\begin{tabular}{lll}
\hline Frequency & X-Z plane & Y-Z plane \\
\hline $\mathbf{G H z})$ & Peak gain $(\mathbf{d B i})$ & Peak gain $(\mathbf{d B i})$ \\
\hline 1.2276 & 2.73 & 2.52 \\
1.5754 & 0.37 & 2.16 \\
1.8 & 3.94 & 2.86 \\
2.4 & 3.25 & 2.86 \\
2.45 & 3.21 & 2.47 \\
5.0 & 3.79 & 3.30 \\
5.2 & 4.46 & 3.40 \\
5.8 & 5.59 & 4.01 \\
\hline
\end{tabular}

\section{Conclusions}

In this study, the fabricated CPW-fed slot antenna with rhombus patch radiator exhibits simple structure and dual-band characteristics. The size of pentagon slot and tuning stub are designed and the frequency bands covering 1.2-2.8 $\mathrm{GHz}$ and 3.35-7.56 GHz are obtained. Various designs of pentagon slot and tuning stub could change the coupling effect and perturb the current distribution around the slot. These results will affect the impedance matching phenomenon. Carefully choose the designed parameters of the pentagon slot and tuning stub would implement the suitable antenna that can be used in GPS, RFID, TD-SCDMA, WLAN, public safety application, and 802.11a/802.11ah standard. The proposed antenna can be built on a single sided printed circuit board which is suitable for mass production and reduces the manufacturing cost.

\section{References}

[1] R. K. Raj, M. Joseph, B. Paul, and P. Mohanan, "Compact planar multiband antenna for GPS, DCS, $2.4 / 5.8 \mathrm{GHz}$ WLAN applications" Electronics Letters, vol. 41, 2005, pp. 33-34. 
[2] RongLin Li, Bo Pan, Joy Laskar, and Manos M. Tentzeris, "A compact broadband planar antenna for GPS, DCS-1800, IMT-2000, and WLAN applications," IEEE Antennas Wireless Propag. Lett., vol. 6, 2007, pp. 25-27.

[3] J. EL Aoufi, N. Alaoui, M. Essaaidi, M. Benayad, "Design of a low cost planar antenna for $2.45 \mathrm{GHz}$ RFID applications," European Journal of Scientific Research, vol. 61, 2011, pp. 42-48.

[4] Y. Y. Lu, S. C. Wei, and H. C. Huang, "Design of RFID antenna for $2.45 \mathrm{GHz}$ applications," Int'l Conf. on Innovative Comp., Information and Control, 2009, pp. 601-604.

[5] Y. L. Kuo and K. L. Wong, "Printed double-T monopole antenna for 2.4/5.2 GHz dual band WLAN operations," IEEE Trans. Antennas Propag., vol. 51, 2003, pp. 2187-2192.

[6] Y. Y. Lu, S. C. Dai, and H. C. Huang, "Design of triple-band planar antenna for LTE/WLAN applications," Int'l Conf. on Intell. Inform. Hiding and Multimedia Signal Proc., 2015, pp. $1-4$.

[7] C. M. Wu, C. N. Chiu, and C. K. Hsu, "A new nonuniform meandered and fork-type grounded antenna for triple-band WLAN applications," IEEE Antennas Wireless Propag. Lett., vol. 5, 2006, pp. 346-348.

[8] S. W. Qu, C. Ruan, and B. Z. Wang, "Bandwidth enhancement of wide-slot antenna fed by CPW and microstrip line," IEEE Antennas Wireless Propag. Lett., vol. 5, 2006, pp. 15-17.

[9] J. Y. Sze, K. L. Wong, "Bandwidth enhancement of a microstrip-line-fed printed wide-slot antenna," IEEE Trans. Antennas Propag., vol. 49, 2001, pp. 1020-1024.

[10] Y. Y. Lu, J. Y. Kuo, H. C. Huang, "Design and application of triple-band planar dipole antennas," Journal of Information Hiding and Multimedia Signal Processing, vol.6, 2015, pp. 792-805.

[11] P. Xu, Z. H. Yan, C. Wang, "Multi-band modified fork-shaped monopole antenna with dual L-shaped parasitic plane," Electronics Letters, vol. 47, 2011, pp. $364-365$.

[12] H. D. Chen, "Broadband CPW-fed square slot antenna with a widened tuning stub," IEEE Trans. Antennas Propag., vol. 51, No.8, 2003, pp. 1982-1986.

[13] J. Y. Chiou, J. Y. Sze, and K. L. Wong, "A broad-band CPW-fed strip-loaded square slot antenna," IEEE Trans. Antennas and Propag., Vol. 51, No. 4, 719-721, 2003.

[14] Y. C. Lin, and K. J. Hung, "Compact ultrawideband rectangular aperture antenna and band-notched designs," IEEE Trans. Antennas and Propag., Vol. 54, No. 11, 3075-3081, 2006. 